\title{
Frequency of dendritiform inflammatory cells in the cornea in herpetic anterior uveitis without clinical keratitis and Fuchs uveitis
}

\author{
Alexandra B Knoll, Andreea S Postole, Gerd U Auffarth and Friederike Mackensen*
}

\begin{abstract}
Background: Herpetic anterior uveitis is a frequent cause of infectious uveitis. A definite diagnosis is obtained by anterior chamber puncture and polymerase chain reaction, an invasive procedure. We hypothesized that patients with herpetic anterior uveitis have a certain pattern of inflammatory cells in their cornea that distinguishes herpetic anterior uveitis from other uveitis types. This study is a prospective, controlled, observational study. Ten patients are with active herpetic anterior uveitis and 14 patients are with Fuchs uveitis syndrome. Patients were imaged with the Heidelberg Retina Tomograph with the Rostock Cornea Module attachment. Three images of the subepithelial area of the cornea were evaluated for dendritiform inflammatory cells. Means were calculated and used for analysis. The contralateral unaffected eyes and numbers published in the literature served as controls.

Results: The number of dendritiform inflammatory cells in herpetic anterior uveitis was compared to that in the Fuchs uveitis syndrome. Of the eyes of patients with herpetic anterior uveitis, $80 \%$ had an average of 98.0 ? 10.8 cells $/ \mathrm{mm}^{2}$ (mean?standard error of the mean (SEM), $n=10$ ) in their affected eyes and $60.4 ? 26.4 \mathrm{cell} / \mathrm{s} / \mathrm{mm}^{2}$, ( $\left.n=6\right)$ in $30 \%$ of their fellow eyes. Patients with Fuchs uveitis syndrome had moderately elevated dendritiform inflammatory cells (47.0?9.7 cells $\left./ \mathrm{mm}^{2}, n=14\right)$ in $96.4 \%$ of their affected eyes and normal numbers $\left(23.0 ? 7.3 \mathrm{cell} / \mathrm{mm}{ }^{2}, n=13\right)$ in $46.4 \%$ of their fellow eyes. The difference between the four groups was significant ( $p=0.0004)$.

Conclusions: Patients with herpetic anterior uveitis had significantly higher levels of dendritiform inflammatory cells in their subepithelial cornea than patients with Fuchs uveitis syndrome, which can be detected by in vivo confocal microscopy. The clinically unaffected eyes of herpetic anterior uveitis patients showed a co-response regarding dendritiform inflammatory cell elevation. We conclude that high numbers of dendritiform inflammatory cells in the cornea of uveitis patients may support the clinical diagnosis of herpetic anterior uveitis.
\end{abstract}

Keywords: Herpetic anterior uveitis; Rostock Cornea Module; Dendritiform inflammatory cells; Anterior uveitis

\section{Introduction}

Anterior uveitis (AU) is the most frequent localization of uveitis [1,2]. Most cases of AU are associated with either a systemic disease (approx. 30\%), a clearly defined ocular syndrome (approx. 30\%), are unclassified or idiopathic disease (approx. 25\%) or with an infection (9.5\%). Among the infectious forms, herpes virus infections and Fuchs uveitis syndrome (FUS) are the most common etiologies [1].

\footnotetext{
* Correspondence: mackensen@uveitiszentrum.de

Interdisciplinary Uveitis Center, Department of Ophthalmology, University Hospital Heidelberg, Im Neuenheimer Feld 400, 69120 Heidelberg, Germany
}

The clinical presentations of these two frequent types of AU show similarities, making it sometimes difficult to distinguish them from each other. Both typically present with a unilateral uveitis associated with iris atrophy and intraocular pressure elevation [3] (reviewed in [4]). FUS is more often a chronic low-grade AU with stellate keratic precipitates (KP), and herpetic anterior uveitis (HAU) more often shows a more acute presentation with granulomatous KP, but many cases at first diagnosis show moderate inflammation and mixed KP and only a longer evaluation period shows the differences. An anterior chamber puncture and aqueous humour analysis for viral polymerase chain reaction (PCR) or intraocular 
antibody synthesis can verify the diagnosis, but patients often prefer to avoid this invasive procedure.

The Heidelberg Retina Tomograph III with the Rostock Cornea Module attachment (HRT-RCM), Heidelberg Engineering, Germany, is a new generation confocal laser scanning microscope which allows corneal imaging on a cellular level. Acquiring those images is non-invasive and fast and bears minimal risk for the patient.

Dendritiform inflammatory cells (DCs) in the subepithelial region (basal epithelium/Bowman's layer or interspersed in the subbasal nerve plexus) can be displayed with this method and appear as large and hyperreflective, branched structures. For easier reading, we decided to refer to these cells as subepithelial throughout the paper even though they may branch into adjacent regions. These cells can be seen by in vivo confocal microscopy in up to $30 \%$ of healthy corneas in low numbers, with increasing density towards the limbal cornea [5-8]. During corneal inflammation (e.g., herpetic keratitis) and irritation (e.g., contact lens wear), increased numbers in the central cornea have been described $[5,8,9]$. To our knowledge, so far, this observation has not been published in non-corneal disease such as anterior uveitis. While we examined corneas of uveitis patients with the HRT-RCM in a previous study looking at keratic precipitates [10], it became apparent that patients with herpetic $\mathrm{AU}$, but not with other types of AU, frequently had high amounts of DCs in their central cornea. We hypothesized that an increase of these cells is typical for herpetic AU and can therefore help to distinguish this type of AU from other AU etiologies.

\section{Methods}

Consecutive patients were prospectively recruited from the clinic of a university-based tertiary centre, the Interdisciplinary Uveitis Centre Heidelberg, Germany. The study protocol was approved by the Institution's Ethical Review Commission. Informed consent was obtained from all patients. The tenets of the Declaration of Helsinki were followed.

Diagnosis of HAU was based on the clinical presentation [11] (unilateral, granulomatous anterior uveitis with intraocular pressure (IOD) elevation [12] and iris atrophy but no corneal involvement) and confirmed either by anterior chamber puncture and PCR ( $2 / 10$ patients) or by improvement due to acyclovir therapy (10/10). HAU was assumed to be herpes simplex virus AU (five patients), confirmed by aqueous humour analysis in two cases (herpes simplex virus (HSV)-1), or varicella-zoster virus $\mathrm{AU}$ (five patients). Two patients had $\mathrm{AU}$ for the first time; eight had a recurrent episode of HAU. None of the patients received antiviral therapy at the time of HRT-RCM examination.

Patients who had been diagnosed with FUS were selected from our database and called in for the examination with the HRT-RCM. Diagnosis of FUS was based on a chronic AU with stellate and/or diffuse keratic precipitates, diffuse iris transillumination defects and/or heterochromia which shows constant low-grade iridocyclitis with only little or moderate symptoms and does not improve with any medical treatment [13]. It is therefore possible to plan their examination; an acute flare is not required. None of the FUS patients was on active medications as, for example, local corticosteroids at the time of examination. Aqueous humour analysis had been performed on three FUS patients and showed local antirubella virus IgG production (elevated Goldmann-Witmer coefficient) in all cases.

Generally, patients did not undergo ocular surgery in the year previous to the RCM exam.

The patients received an anaesthetic eye drop in both eyes and a drop of an aqueous gel tear substitute (e.g., Vidisic gel) to optically couple the microscope lens and the cornea. The objective of the microscope was an immersion lens (Olympus, Hamburg, Germany), magnification 60, to which a disposable contact plastic cap ( TomoCap, Heidelberg Engineering, Heidelberg, Germany) was attached. The patients were asked to look straight at a marked point in a 5-m distance, in order to standardize the examination conditions and to scan a corresponding corneal area in all patients as good as possible. HRT-RCM (mag 400/Achroplan 63W/NA 0.95/AA $2.00 \mathrm{~mm} 670 \mathrm{~nm} /$ Zeiss, Oberkochen, Germany) scanning was then performed. The focus was manoeuvred through the corneal epithelium along the $z$-axis until the subbasal nerve plexus became visible at a depth of 40 to $60 \mu \mathrm{m}$. Sequential images were captured on this level from central areas of the cornea. The scans captured an area of $400400 \mu \mathrm{m}$ (384 384 pixels) per image, with a transverse optical resolution of $2 \mu \mathrm{m}$ and longitudinal optical resolution of $4 \mu \mathrm{m}$ (Heidelberg Engineering supplied information). Usually, an exam takes 2 to 5 min resulting in 30 to 100 images of the region of interest.

Two observers (AK and SP), one of them blinded (SP) to the patients' diagnosis, selected three representative images per patient and counted the number of cells per square millimetre using the system's cell counting software as described in [7]. DCs touching two of the four edges of the image were excluded to avoid under/overestimation of the density. Manual lateral scanning was used to trim and image the nerve plexus in the central region of the cornea. Means of the six countings were calculated and used for analysis. Published numbers of DCs in healthy central corneas at a depth of 35 to $60 \mu \mathrm{m}$, 34.3 cells $/ \mathrm{mm}^{2}$ (range 0 to 64 cells $/ \mathrm{mm}^{2}$ ), served as normal controls [7]. The methodology of this study is comparable to our study. GraphPad Prism Software was used for statistical analysis. Results were evaluated for statistical 
significance with a Mann-Whitney $U$ Test or an ANOVA when appropriate.

The interobserver reliability was calculated with a Spearman test performed on the mean cells per square millimetre per patient by each observer.

\section{Results}

Ten patients with active HAU (10 active and 6 contralateral unaffected eyes) and 14 patients with FUS (15 affected and 13 unaffected eyes, 1 patient had bilateral, albeit asymmetric (OS $>\mathrm{OD})$, Fuchs) were examined with the HRT-RCM between 2009 and 2012. Five HAU patients were female, and five were male, mean age at examination was 50.3 years (range 15 to 70 years). Five FUS patients were female and nine were male, mean age was 49.8 years (range 30 to 69 years). None of the patients with HAU showed signs of corneal affection on slit lamp examination. Corneal sensitivity was tested with esthesiometer in five of the HAU patients and was markedly reduced in two, slightly reduced in two, and normal in one patient. The remaining HAU patients were not tested.
Interobserver correlation of DC counts was excellent (Spearman $r=0.9622, p \leq 0.0001$ ).

In both groups, DCs were seen in higher frequency in the subepithelial area of central corneas of the affected eyes compared to the fellow eyes (Figure 1). We saw DCs in all affected HAU eyes and five of six (83\%) fellow eyes. In FUS patients, DCs were seen in 12 of 14 (86\%) affected and 12 of 13 (92\%) fellow eyes. Patients with HAU had significantly more DCs $\left(98.010 .8 \mathrm{cells} / \mathrm{mm}^{2}\right.$, mean standard error of the mean (SEM), range 58.8 to 162.6 cells $/ \mathrm{mm}^{2}$ ) in their affected eye than patients with FUS (47.0 9.7 cells $/ \mathrm{mm}^{2}$, mean SEM, range 0 to 115.6 cells $/ \mathrm{mm}^{2}, p<0.0001$ ) (Figure $2 \mathrm{~A}$ ). Patients with HAU also showed elevated numbers of DCs (60.4 26.4 cells $/ \mathrm{mm}^{2}$, range 0 to 177.3 cells $/ \mathrm{mm}^{2}$ ) in their contralateral, clinically unaffected eye. Contralateral eyes of FUS patients exhibited only few DCs (23.0 7.3 cells/ $\mathrm{mm}^{2}$, range 0 to 77.5 cells $/ \mathrm{mm}^{2}$ ), lower than numbers found in healthy corneas (34. 3 cells $/ \mathrm{mm}^{2}$ (range 0 to 64 cells $/ \mathrm{mm}^{2}$ ) [7] (Figure 2B). One patient with bilateral FUS showed a mean of 45 cells $/ \mathrm{mm}^{2}$ DCs in the right, less affected eye and 59 cells $/ \mathrm{mm}^{2}$ DCs in his left, more affected eye.
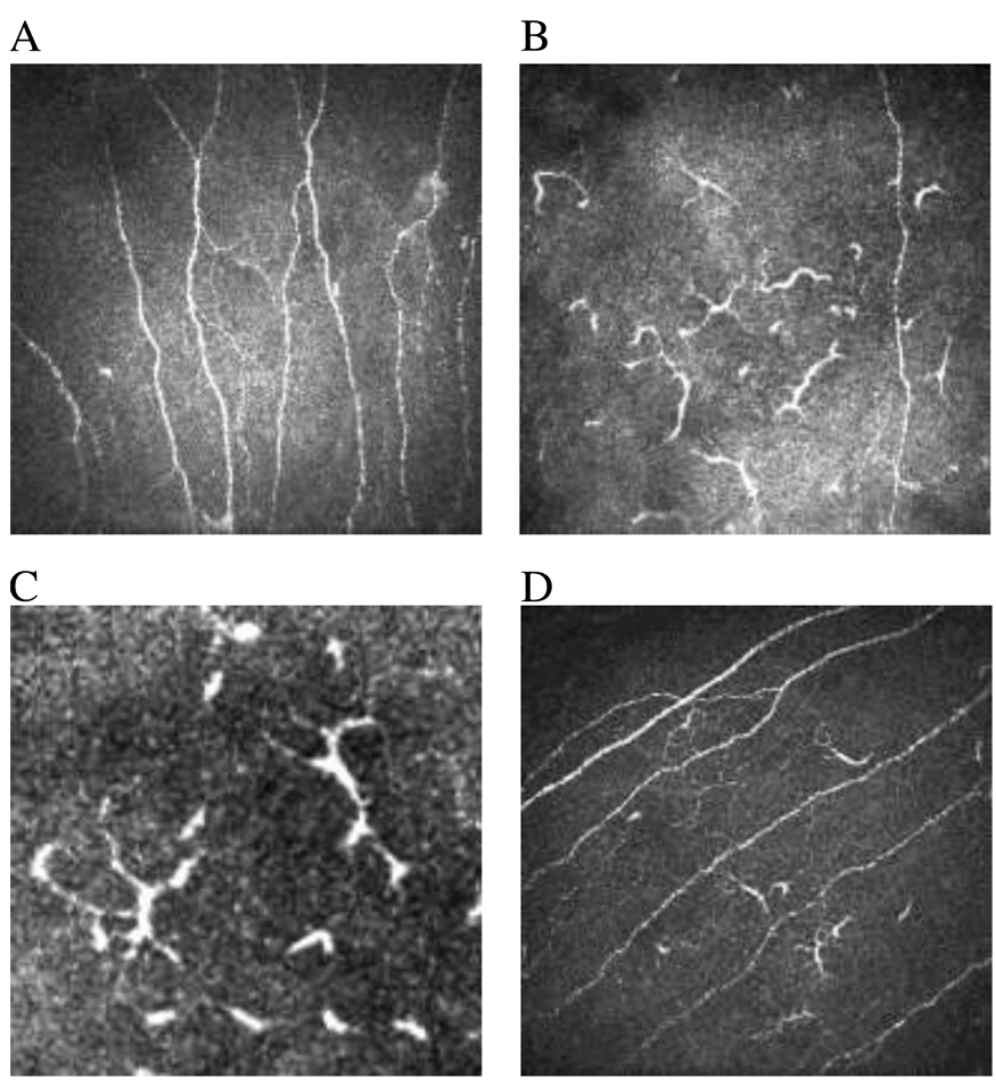

Figure 1 Dendritiform cells (DCs) display. As large, hyperreflective, branched structures in the subepithelial region of the cornea above of or interspersed in the subbasal nerve plexus. Bar represents $50 \mu \mathrm{m}$. (A) The corneal subbasal nerve plexus in a healthy cornea (400 ? $400 \mu \mathrm{m})$. (B) DCs in one section $(400$ ? $400 \mu \mathrm{m})$ in the cornea of a patient with herpetic anterior uveitis. (C) Close up of DCs. (D) Subbasal nerve plexus of a patient with FUS showing some DCs. 

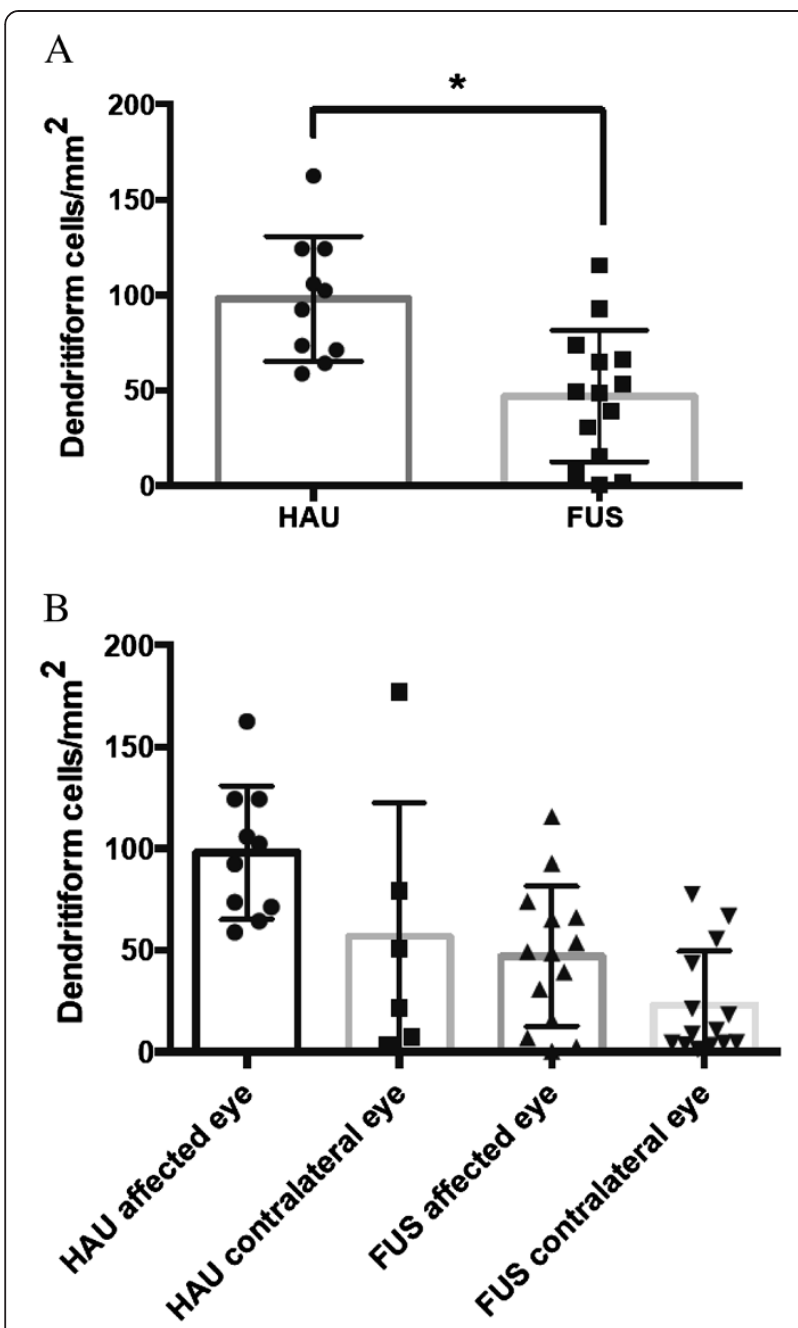

Figure 2 Amount of dendritiform cells (DCs) per square millimetre. In the subepithelial corneas of patients with herpetic anterior uveitis (HAU) vs. Fuchs uveitis syndrome. (A) Significantly, more DCs were present in the affected eyes of HAU compared with FUS ( ${ }^{*} p<0.0001$ Mann Whitney $U$ test). (B) Both eyes of patients with herpetic uveitis showed increased DCs in their corneas, indicating a co-response of the fellow eye. DCs in the affected eyes of FUS patients were moderately elevated but not in the unaffected eyes.

The amount of DCs did not correlate with the anterior chamber cell count or anterior chamber flare, assessed by slit lamp examination (data not shown). Anterior chamber cells ranged between 0 and $2+(2+$ only in one patient) in the HAU group and between 0 and $1+$ in the FUS group.

\section{Discussion}

Laser in vivo confocal microscopy has been used over the past years by different investigators to image corneal sections [6,7,9,14-16] for a review [8]. Hyperreflective cells of dendritic appearance have frequently been described in the basal epithelium or subepithelial region at the level of Bowman's layer and sometimes are referred to as Langerhans cells or dendritic cells [7]. Studies performing immunohistological staining on animals $[14,17]$ and a recent study on humans plausibly suggest that cells with branching, dendritic morphology in the corneal basal epithelial layer are antigen-presenting cells [18]. Most likely, a small heterogeneous population of antigen-presenting cells is present in uninflamed corneas which undergo changes in phenotype and function during corneal inflammation [6,17-20].

In 1987, an animal study showed a significant increase of Langerhans cells in the central cornea during HSV-1 keratitis, assessed by cytochemistry [21]. A more recent study on mice suggested an essential role of corneal dendritic cells in the immune defence against HSV-1 keratitis, by directing the local NK response [22]. Mayer et al. found more antigen-presenting cells in post-herpes keratitis corneas than in graft rejection after keratoplasty or keratoconus, assessed via confocal microscopy and histochemistry [18]. Mocan et al. found dendritiform and small round cells by in vivo confocal microscopy in 52\% of patients with non-epithelial herpes keratitis. This included eight patients with keratouveitis, which showed DCs in 38\%. In their healthy controls, these authors apparently did not see any DCs [9]. Rosenberg et al. found DCs in $62.5 \%$ of eyes with HSV keratitis and $12.5 \%$ of fellow eyes [5]. This is in contrast to our study where DCs were seen in $86 \%$ to $100 \%$ of affected and fellow eyes and also to another study on patients with herpetic keratitis reporting DCs in $92 \%$ of affected and $21 \%$ of healthy control eyes [6]. This difference in DCs detected may be explained by the confocal microscope used, Mocan et al. using a slit scanning confocal microscope (Confoscan 3.0), Rosenberg et al. a tandem scanning confocal microscope, and we and Mastropasqua as well as Zhivov et al. used a laser scanning confocal microscope (HRT-RCM) [6,7].

Regarding mean numbers of DCs detected, our numbers are lower than those found in HSV keratitis (241.9 81.1 cells $/ \mathrm{mm}^{2}$ ) or corneal graft rejection (147.2 32.5 cells/ $\mathrm{mm}^{2}$ ) by Mastropasqua et al. This could be explained by secondary or collateral involvement of the cornea in HAU, the primary herpetic reactivation being in the ciliary nerves of the iris.

To our knowledge, no studies have been published on the behaviour of dendritiform cells during anterior uveitis without corneal involvement.

We found that in patients with herpetic AU, despite no clinical signs of keratitis, the central corneas contained high numbers of DCs. In our control group with FUS, a clinically similar uveitis form supposedly of viral origin (Rubella) as well [23,24], the number of DCs was only moderately increased with regard to the average measured in healthy probands [6,7]. Therefore, we see a potential 
diagnostic value for this method in diagnosing HAU noninvasively, but other non-infectious anterior uveitis subsets should be evaluated to create cutoff values for DC counts that confirm a diagnosis of HAU.

Elevated DCs even in the contralateral, uninflamed eye of patients HAU indicated a co-response of the fellow eye. This is in keeping with recent results by Hamrah et al. who found a nerve fibre reduction in both eyes of patients with unilateral zoster ophthalmicus keratitis, similarly suggesting bilateral changes in a clinically unilateral herpetic eye disease [25]. Neither the study of Mocan et al. nor the study of Mastropasqua et al. did look at DC numbers in the contralateral eye [6,9]; Rosenberg et al. saw DCs in $12 \%$ of fellow eyes but did not quantify them [5].

Dendritic cells, which probably compose at least in parts the DCs we here describe, might appear for immunological reasons in the cornea while the herpes virus affects not the cornea itself but the adjacent anterior chamber. Herpetic keratitis has been studied more intensely than herpetic uveitis, but the exact pathogenesis remains insufficiently understood [26]. After primary infection, the herpes virus passes into a state of latency (intact quiescent viral genome without obvious pathological effects) in a host neuronal ganglion cell until its reactivation (migration to the site of infection and replication), often triggered by stress (reviewed in [27]). Not only the trigeminal ganglion is generally accepted to be a site of HSV latency $[28,29]$, but also the ciliary ganglion has been found to host HSV DNA in asymptomatic humans, offering possible explanations for anterior chamber or retinal herpetic diseases, tissues not directly innervated by trigeminal nerves [30]. A topic of great debate is whether the cornea itself may be a reservoir for the inactive herpes virus [31,32]. Some manifestations of herpetic keratitis, particularly herpetic stromal disease, are assumed to be virus-independent and rather than immune-mediated diseases. Over 20 years ago, studies showed that an increase of Langerhans cells in the cornea prior to infection with HSV-1 led to a significantly higher susceptibility and severity of herpetic stromal disease [33,34].

There are limitations to our study. We - as other studies - can only present a small number of patients, which lies in the nature of the disease. Still, we present two homogenous uveitis subtypes. Unfortunately, we could only give molecular proof of viral infection in two of the HAU patients, as the remaining patients declined anterior chamber tap. In the best of possible cases, we would not only have done PCR to show viral DNA but also tested for local antibody production. By combining PCR, viral load and local antibody production, a better correlation with the level of viral replication and antiviral immunity could have been achieved [3,35]. Equally, our choice of FUS as a control could be discussed as not ideal, as it is a chronic disease, with only mild inflammatory activity. In our study, the amount of corneal DCs did not correlate with the anterior chamber cell count or flare. We therefore believe that their increase does not reflect increasing intensity of unspecific inflammation but possibly indicates active immune mechanisms against the herpes viruses. Therefore, we also think that the differences in numbers of DCs seen between HAU and FUS are not due to less inflammatory activity in FUS. Still, to further support this theory, DCs in patients with other forms of AU need to be studied. Further, this is a cross-sectional study; no serial confocal microscopic exams were performed. Lastly, we only collected information on the central cornea. However, as shown in the study from Mastropasqua et al., this is the region of interest for corneal inflammatory diseases, showing the most significant differences towards healthy controls [6]. Other authors reported a decreased subepithelial nerve fibre density in the central corneas in herpetic keratitis as an additional finding $[9,36]$. We have not looked into this in the study presented here. The HRT-RCM is a non-invasive and low-risk technique to acquire corneal images. DCs are easily displayed, and high amounts were seen in our study in patients with HAU. We conclude that confocal microscopy may be a useful additional tool in diagnosing HAU. How DCs behave in quiescent or treated disease as well as in other anterior uveitis subtypes remains to be evaluated.

\section{Conclusions}

We conclude that confocal microscopy may be a useful additional tool in diagnosing HAU. How DCs behave in quiescent or treated disease as well as in other anterior uveitis subtypes remains to be evaluated.

\section{Abbreviations}

AU: anterior uveitis; DC: dendritiform inflammatory cells;

DNA: desoxyribonucleic acid; FUS: Fuchs uveitis syndrome; HAU: herpetic anterior uveitis; HRT: Heidelberg Retina Tomograph; HSV: herpes simplex virus; IOD: intraocular eye pressure; KP: keratic precipitates; OD: oculus dexter; OS: oculus sinister; PCR: polymerase chain reaction; RCM: Rostock cornea module; SEM: standard error of the mean.

\section{Competing interests}

Friederike Mackensen has received lecture honoraria by Heidelberg Engineering, and Alexandra Knoll has received a Travel Grant by Heidelberg Engineering. We have been loaned the Heidelberg Retina Tomograph III and the Rostock Cornea Module attachement (HRTIII RCM) by Heidelberg Engineering for this study and another study. The other authors declare that they have no competing interests.

\section{Authors' contributions}

ABK made substantial contribution to the acquisition of data and analysis and interpretation of data and drafted the manuscript. ASP made substantial contribution to the acquisition of data, participated in its coordination and helped to draft the manuscript. GUA had been involved in the design and coordination of the manuscript and helped to draft the manuscript. FM participated in its design and coordination, revised the manuscript critically for important intellectual content and agreed to be accountable for all 
aspects of the work in ensuring that questions related to the accuracy or integrity of any part of the work are appropriately investigated and resolved. All authors read and approved the final manuscript.

\section{Received: 1 August 2014 Accepted: 30 November 2014}

\section{(1)}

\section{References}

1. Jakob E, Reuland MS, Mackensen F, Harsch N, Fleckenstein M, Lorenz HM, Max R, Becker MD (2009) Uveitis subtypes in a german interdisciplinary uveitis center analysis of 1916 patients. J Rheumatol 36(1):127 36

2. Rodriguez A, Calonge M, Pedroza-Seres M, Akova YA, Messmer EM, D'Amico DJ, Foster CS (1996) Referral patterns of uveitis in a tertiary eye care center. Arch Ophthalmol 114(5):593 599

3. Wensing B, Relvas LM, Caspers LE, Valentincic NV, Stunf S, de Groot-Mijnes JD, Rothova A (2011) Comparison of rubella virus- and herpes virus-associated anterior uveitis: clinical manifestations and visual prognosis. Ophthalmology 118(10):1905 1910

4. Jap A, Chee SP (2011) Viral anterior uveitis. Curr Opin Ophthalmol 22(6):483 488

5. Rosenberg ME, Tervo TM, Muller LJ, Moilanen JA, Vesaluoma MH (2002) In vivo confocal microscopy after herpes keratitis. Cornea 21(3):265 269

6. Mastropasqua L, Nubile M, Lanzini M, Carpineto P, Ciancaglini M, Pannellini T, Di Nicola M, Dua HS (2006) Epithelial dendritic cell distribution in normal and inflamed human cornea: in vivo confocal microscopy study. Am J Ophthalmol 142(5):736 744

7. Zhivov A, Stave J, Vollmar B, Guthoff R (2007) In vivo confocal microscopic evaluation of langerhans cell density and distribution in the corneal epithelium of healthy volunteers and contact lens wearers. Cornea 26(1):47 54

8. Niederer RL, McGhee CN (2010) Clinical in vivo confocal microscopy of the human cornea in health and disease. Prog Retin Eye Res 29(1):30 58

9. Mocan MC, Irkec M, Mikropoulos DG, Bozkurt B, Orhan M, Konstas AG (2012) In vivo confocal microscopic evaluation of the inflammatory response in non-epithelial herpes simplex keratitis. Curr Eye Res 37(12):1099 106

10. Mackensen FXJ, Chua C (2009) In vivo laser confocal microscopy of keratic precipitates is a useful tool in differencing specific uveitis diagnosis as well As active from inactive uveitis. ARVO Meeting Abstracts 50(5):1525

11. Van der Lelij A, Ooijman FM, Kijlstra A, Rothova A (2000) Anterior uveitis with sectoral iris atrophy in the absence of keratitis: a distinct clinical entity among herpetic eye diseases. Ophthalmology 107(6):1164 70

12. Khan BF, Pavan-Langston D (2004) Clinical manifestations and treatment modalities in herpes simplex virus of the ocular anterior segment. Int Ophthalmol Clin 44(3):103 133

13. Becker MD, Zierhut M (2005) Fuchs uveitis syndrome heterochromia is no conditio sine qua non. Ophthalmologe 102(7):733 742, quiz 7434

14. Hamrah P, Liu Y, Zhang Q, Dana MR (2003) The corneal stroma is endowed with a significant number of resident dendritic cells. Invest Ophthalmol Vis Sci 44(2):581 9

15. Hau SC, Dart JK, Vesaluoma M, Parmar DN, Claerhout I, Bibi K, Larkin DF (2010) Diagnostic accuracy of microbial keratitis with in vivo scanning laser confocal microscopy. Br J Ophthalmol 94(8):982 7

16. Kanavi MR, Javadi M, Yazdani S, Mirdehghanm S (2007) Sensitivity and specificity of confocal scan in the diagnosis of infectious keratitis. Cornea 26(7):782 6

17. Choudhury A, Pakalnis VA, Bowers WE (1995) Function and cell surface phenotype of dendritic cells from rat cornea. Invest Ophthalmol Vis Sci 36(13):2602 2613

18. Mayer WJ, Mackert MJ, Kranebitter N, Messmer EM, Gruterich M, Kampik A, Kook D (2012) Distribution of antigen presenting cells in the human cornea: correlation of in vivo confocal microscopy and immunohistochemistry in different pathologic entities. Curr Eye Res 37(11):1012 8

19. Hamrah P, Liu Y, Zhang Q, Dana MR (2003) Alterations in corneal stromal dendritic cell phenotype and distribution in inflammation. Arch Ophthalmol 121(8):1132 40

20. Yamagami S, Yokoo S, Usui T, Yamagami H, Amano S, Ebihara N (2005) Distinct populations of dendritic cells in the normal human donor corneal epithelium. Invest Ophthalmol Vis Sci 46(12):4489 94

21. Asbell PA, Kamenar T (1987) The response of Langerhans cells in the cornea to herpetic keratitis. Curr Eye Res 6(1):179 82
22. Frank GM, Buela KA, Maker DM, Harvey SA, Hendricks RL (2012) Early responding dendritic cells direct the local NK response to control herpes simplex virus 1 infection within the cornea. J Immunol 188(3):1350 9

23. Quentin CD, Reiber H (2004) Fuchs heterochromic cyclitis: rubella virus antibodies and genome in aqueous humor. American Journal of Ophthalmology 138:46 54

24. de Groot-Mijnes JD, de Visser L, Rothova A, Schuller M, van Loon AM, Weersink AJ (2006) Rubella virus is associated with fuchs heterochromic iridocyclitis. American Journal of Ophthalmology 141(1):212 214

25. Hamrah P, Cruzat A, Dastjerdi MH, Pruss H, Zheng L, Shahatit BM, Bayhan HA, Dana R, Pavan-Langston D (2013) Unilateral herpes zoster ophthalmicus results in bilateral corneal nerve alteration: an in vivo confocal microscopy study. Ophthalmology 120(1):40 7

26. Garweg JG, Halberstadt M (2002) The pathogenesis of herpetic keratitis. Klin Monbl Augenheilkd 219(7):477 86

27. Toma HS, Murina AT, Areaux RG Jr, Neumann DM, Bhattacharjee PS, Foster TP, Kaufman HE, Hill JM (2008) Ocular HSV-1 latency, reactivation and recurrent disease. Semin Ophthalmol 23(4):249 73

28. Hill JM, Gebhardt BM, Wen R, Bouterie AM, Thompson HW, O Callaghan RJ, Halford WP, Kaufman HE (1996) Quantitation of herpes simplex virus type 1 DNA and latency-associated transcripts in rabbit trigeminal ganglia demonstrates a stable reservoir of viral nucleic acids during latency. J Virol 70(5):3137 41

29. Baringer JR, Swoveland P (1973) Recovery of herpes-simplex virus from human trigeminal ganglions. N Engl J Med 288(13):648 50

30. Bustos DE, Atherton SS (2002) Detection of herpes simplex virus type 1 in human ciliary ganglia. Invest Ophthalmol Vis Sci 43(7):2244 9

31. Cantin EM, Chen J, McNeill J, Willey DE, Openshaw H (1991) Detection of herpes simplex virus DNA sequences in corneal transplant recipients by polymerase chain reaction assays. Curr Eye Res 10(Suppl):15 21

32. Kennedy DP, Clement C, Arceneaux RL, Bhattacharjee PS, Huq TS, Hill JM (2011) Ocular herpes simplex virus type 1: is the cornea a reservoir for viral latency or a fast pit stop? Cornea 30(3):251 9

33. Jager MJ, Bradley D, Atherton S, Streilein JW (1992) Presence of Langerhans cells in the central cornea linked to the development of ocular herpes in mice. Exp Eye Res 54(6):835 41

34. McLeish W, Rubsamen P, Atherton SS, Streilein JW (1989) Immunobiology of Langerhans cells on the ocular surface. II. Role of central corneal Langerhans cells in stromal keratitis following experimental HSV-1 infection in mice. Reg Immunol 2(4):236 43

35. Takase H, Kubono R, Terada Y, Imai A, Fukuda S, Tomita M, Miyanaga M, Kamoi K, Sugita S, Miyata K, Mochizuki M (2014) Comparison of the ocular characteristics of anterior uveitis caused by herpes simplex virus, varicellazoster virus, and cytomegalovirus. Jpn J Ophthalmol 58(6):473 82

36. Hamrah P, Cruzat A, Dastjerdi MH, Zheng L, Shahatit BM, Bayhan HA, Dana R, Pavan-Langston D (2010) Corneal sensation and subbasal nerve alterations in patients with herpes simplex keratitis: an in vivo confocal microscopy study. Ophthalmology 117(10):1930 6

\section{Submit your manuscript to a SpringerOpen ${ }^{\circ}$ journal and bene冈t from:}

- Convenient online submission

Rigorous peer review

- Immediate publication on acceptance

- Open access: articles freely available online

- High visibility within the \eld

- Retaining the copyright to your article

Submit your next manuscript at springeropen.com 